\title{
EDITORIAL
}

\section{Empowering the digitally excluded: learning initiatives for (in)visible groups}

\author{
Jane Seale ${ }^{\mathrm{a} *}$ and William Dutton ${ }^{\mathrm{b}}$ \\ ${ }^{a}$ School of Education, University of Plymouth, Drakes Circus, Plymouth; ${ }^{b}$ Oxford Internet \\ Institute, University of Oxford
}

There is growing evidence that some digitally excluded groups of learners are receiving more attention than others. Discussions regarding why some digitally excluded learners are more visible than others and therefore worthy of more committed digital inclusion interventions raises important questions about how we define and conceptualise digital inclusion and digital inclusion practice; particularly in relation to empowerment. In this article, we draw on a range of research, practice and policy literature to examine two important questions: what is empowerment and in whose hands does empowerment lie? We argue that empowerment involves making informed choices about technology use, but that learners often require support- human intervention- to make these choices. However, current digital inclusion research has failed to produce a detailed critique of what constitutes empowering support from educational institutions and their staff. A lack of open and reflexive accounts of practice means that we are no closer to identifying and understanding the kinds of empowering practices that are required to challenge the kinds of prejudices, stereotypes, risk-aversiveness and low aspirations associated with the most invisible of digitally excluded learners.

Keywords: digital inclusion; digital exclusion; empowerment; risk-aversion; practice; conceptualisation

\section{Introduction}

The focus of this special issue for Research in Learning Technology is Digital Inclusion and Learning. In this issue we present six papers:

1. Information and communication technology related needs of college and university students with disabilities by Catherine Fichten, Jenison Asuncion, Joan Wolforth, Maria Barile, Jillian Budd, Natalie Martiniello and Rhonda Amsel.

2. Adapting online learning resources for all: planning for professionalism in accessibility by Patrick McAndrew, Robert Farrow and Martyn Cooper.

3. Digital exclusion or learning exclusion? An ethnographic study of adult male distance learners in English prisons by Anne Pike and Anne Adams.

4. Training in basic internet skills for special target groups in non-formal educational settings - Conclusions from three pilot projects by Andrea Berger and Jutta Croll. 


\section{Editorial}

5. Aggregate then Curate: Communities, digital learning champions and social media by Andrew Whitworth, Fred Garnett and Diana Pearson.

6. Learning and Digital Inclusion: The ELAMP project by Kate Darcy.

The first two papers focus on expanding concepts digital inclusion in the formal educational settings of universities in Canada and the European Union. The third paper focuses on formal and informal learning that takes place in UK prisons. The final two papers focus on informal community settings in the UK and Germany. Across the five studies, the needs and experiences of a diverse range of learners are addressed. The studies reported by Fichten et al. and McAndrew et al. focus on disabled university students. Pike and Adams focus on male prisoners. Berger \& Croll focus on what they identify as three "special target groups": visually impaired elderly people, young migrant Russians living in Germany and low waged female workers. Whitworth et al. describe a digital inclusion project where the learners are members of a local community. Darcy reflects on the experiences and opportunities that a digital inclusion initiative offered traveller children and their families. These learners fall into two groups that we will call visible and invisible (See Box 1). The former consists of disadvantaged learners that are frequently the focus of digital inclusion interventions. The latter consists of disadvantaged learners that are less commonly the focus of digital inclusion interventions.

Box 1. Foci of Digital Inclusion Initiatives.

\begin{tabular}{ll}
\hline Visible: & Visually impaired; elderly people; low waged workers; members of strong local \\
& communities \\
Invisible: & $\begin{array}{l}\text { Disabled university students; domestic violence sufferers; migrants; prisoners; } \\
\text { substance abusers; traveller children, young people and their families, particularly } \\
\text { those from show and fairground communities; youngest children; children in care } \\
\text { and children with mental health problems }\end{array}$ \\
\hline
\end{tabular}

\section{Divides within divides: Speaking up for the ignored}

This distinction between visible and invisible reflects growing evidence that some digitally excluded groups are receiving more attention than others. For example, in the UK, the Digital Inclusion Team (2007) reviewed a range of inclusion projects and concluded that many projects had focused on the largest groups that lacked access to the Internet, such as the elderly and the disabled. They argued that smaller and less prominent groups were less well served. In addition, although these groups are smaller, the people within them could disproportionably benefit more from initiatives to improve their situations than many in the larger groups. The smaller groups that they identified as being ignored and yet potentially able to benefit more from innovative uses of ICT were: substance abusers; travellers; domestic violence sufferers; youngest children; those with mental health problems and children in care. The reasons why some digitally excluded learners are ignored or invisible are varied. For example, despite a large tranche of studies that show that online learning resources remains largely inaccessible to disabled university students (Seale, 2006) this group of learners are rarely considered disadvantaged by governments and other similar bodies because they are at university, a position that is considered to be 
privileged compared to other groups. The progress of digital inclusion projects aimed at travellers and children in care tends to be highly mediated by gate-keepers or guardians such as teachers and social workers. For example, reporting on a project that provided technology to gypsy and traveller children so that they could access learning resources and keep in contact with their school, (Marks, 2009: p. 4) concluded that: "success comes with a health warning and there have also been failures. Much has depended on the commitment of schools and families"

Darcy (2012, this issue) indicates that in the context of gypsy and traveller children commitment to supporting digital inclusion can be influenced by the stigma and prejudices associated with this group of learners. The work conducted by Padfield and colleagues in Scotland would support this view. They explored a range of stakeholders' views regarding the potential benefits of providing and using technology with traveller children. Stakeholders included traveller children and their families, school teachers and out-reach teachers and site managers. The results provoke some challenging questions regarding what the real barriers to digital inclusion are for travellers: lack of access or lack of support. Padfield and Jordan (2002) show that Scottish education authorities varied widely in their provision of laptops for Scotland's heterogeneous pupil population. Participants' reports suggested that pupils educated in outreach school settings should be well provided with laptops and ICT. However, such pupils, who were typically described as experiencing significant interruptions to their teaching and learning, were also reported as more likely to be considered by some educators, policy makers and local communities as less deserving of laptop provision than were their peers at school, for a variety of reasons. Padfield and Jordan (2003) noted that gypsy/traveller children were pleased but surprised to be provided with technologies such as laptops and suggested that this surprise encapsulated the generally low expectations that they had of educational authorities support for their learning. Padfield and Jordan also noted that despite the provision of support services being seen as a move towards greater inclusion, teachers and pupils working in outreach school settings felt professionally and educationally devalued. Finally, Padfield and Jordan (2004) reported that ICT was one area of learning that provoked interest among gypsy/traveller children and parents, particularly in the case of boys. Despite this interest they reported a lack of ICT provision for pupils. They noted that not one school involved in the research had developed distance learning for traveller pupils. There are some similarities with these results and those found by Lund (2009) who evaluated a Norwegian project that used technology to facilitate communication between teachers and traveller children and to promote distance or blended learning. Whilst, positive results were reported overall, Lund noted that some teachers were prejudiced against travellers and wondered if this might on occasions have led to low expectations for their success or a lack of motivation to use the technology to communicate and work with the traveller families.

In the context of looked-after children commitment to supporting digital inclusion can be influenced by tendencies of risk aversion and fears associated with letting vulnerable children online. This is something the Inter-Life project (funded by the UK government under the Technology Enhanced Learning Research Programme) experienced when researchers developed a Second Life environment designed to facilitate transitions from school to university. A key target group for the Inter-Life project was originally looked-after young people who were also gifted and talented. The project team expected that the virtual worlds they had created held the 


\section{Editorial}

potential to give these young people a space to be imaginative and unleash their abilities. This belief was perfectly illustrated by one of the participants in the project (TEL, 2011). Frank (not his real name) was a looked-after 17-year-old. He was inspired to enrol on an IT course and go to university after spending three months working with others on the island. This is particularly noteworthy given that across the UK, as of 2011, only 7 per cent of teenagers in care are reported to go on to higher education compared to 40 per cent of 18-year-olds (TEL, 2011). Frank, who spent 11 years in care, is reported as saying that teenagers are often happier talking through an 'avatar'. Frank said: "Inter-Life Island is a good place for young people to gain confidence and help them deal with issues they might have in children's homes or in foster care. The listening is better." The Inter-Life project team found however, that many looked-after children struggled to get meaningful access to the Internet, and therefore missed out on valuable opportunities, such as engaging in virtual learning environments. For looked-after children their spaces are normally controlled to an extreme level. This is primarily because the children's homes they live in, have a tendency to put in place rules and procedures that mean that the length of time that looked-after children can spend on the Internet is often severely restricted (for example one hour a day). Also, the quality of Internet use is often significantly compromised either through having to share a computer with many other children or by the mandatory supervision of computer use by adults. As Frank succinctly put it, technically, looked- after children have access to the Internet, but "it doesn't amount to anything worth having". Access to technology, then is vital. Equally as vital is the way that "powerful others" encourage and facilitate engagement with technology once access has been secured. While this has parallels generally with parents in households, the effect is often overlooked in other settings of less visible target groups.

Discussions regarding which learners are considered to be digitally excluded and therefore worthy of digital inclusion interventions raises important questions about how we define and conceptualise digital inclusion. Where definitions of digital inclusion exist, they tend to embed within them an expectation or imperative that digital inclusion happens when all members of society are able to access the affordances offered by technology use (see for example Selwyn \& Facer, 2007). But does "all really mean "all"? and who decides which group of learners are legitimate targets of digital inclusion initiatives? Seale (2009) argued that digital inclusion encompasses five inter-related concepts: access, use, participation, equity and empowerment. If, as in the examples provided here of looked-after children and travellers, the digital inclusion of the most digitally excluded in our society is highly dependent on the thoughts and actions of "powerful others", it would seem appropriate to unpick exactly what is meant by digital inclusion and empowerment. What is empowerment and in whose hands does empowerment through digital inclusion lie? By addressing these questions we will address a major objective of this special issue on digital inclusion by contributing to the development of a detailed conceptual framework that broadens our understanding of the complexity of digital exclusion.

\section{In the context of digital inclusion, what is empowerment?}

Digital inclusion is a ubiquitous term that is rarely explicitly defined. In a review of digital inclusion and education research and practice (Seale 2009: p. 3) concluded 
that the vagueness around the term means that digital inclusion is in "danger of becoming a meaningless concept which at best is ignored, and at worst is rejected". Seale did observe however, that digital inclusion is concerned with addressing inequalities, where those unable to access the normal affordance of technologies are disadvantaged and marginalised in society. Castells (2001: p. 247), for example talks of unequal levels of technology access and skills that 'adds a fundamental cleavage to existing sources of inequality and social exclusion'. Selwyn (2004: p. 351) refers to both inequalities of opportunity to access and use technologies and inequalities of outcome "resulting either directly or indirectly from engagement with these technologies". We have argued elsewhere that how the Internet and related information and communication technologies reconfigure access to resources for particular individuals and groups is the central issue of the digital age (Dutton, 1999).

Digital divide research has identified where inequalities exist in terms of access and use. Surveys have shown continuing demographic gaps with socioeconomic status, income, level of education, ethnicity, age and geography all consistently found to affect levels of technology access and use; although some gaps such as those around gender appear to be narrowing (see for example, Dutton et al. 2009; Dutton $\&$ Blank, 2011). There has been a tendency for the data from digital divide surveys to be interpreted rather simplistically, with assumptions being drawn that all that is required is the provision of technology and training on how to use it. Many digital divide researchers have however warned that digital exclusion is a complex phenomenon that needs to be understood in broader terms than access to equipment and use, to include social and cultural factors that lead many individuals and groups to choose exclusion, what might be called the digital choice versus the digital divide (Dutton et al. 2007). For example, The British Educational Communications and Technology Agency (Becta) assert that because digital inclusion is complex, involving a range of social, economic and cultural factors, the digital divide: "cannot be fully captured by a definition that focuses solely on access or ownership (Becta, 2001: p. 4).

In policy, research and practice literature, digital inclusion and empowerment are associated in three different ways: empowerment as being able to function independently; empowerment as freedom from external control and empowerment as the individual exertion of control and choice. The UK government in its consultation paper on Digital Inclusion talked of technology being a 'vehicle for empowerment, rather than a force for further exclusion' HM Government (2008: p. 5). The consultation document proposed a Digital Inclusion Charter which enshrined in it the principle of 'citizen and community empowerment', where the most disadvantaged citizens and communities are assisted and motivated to "achieve increased independence and opportunity through direct access to digital technology and skills" (HM Government, 2008: p. 61). We contend that there are neo-liberal undertones to the UK government's conceptions of independence and therefore empowerment. For policy makers, independence is largely understood as occurring when individuals cease to be a burden to society and therefore can usefully contribute to society. It is worth noting however, that many inclusion and disability advocates reject the notion that independence is about self-sufficiency, arguing instead that it is about being able to take control over ones' life and choose how that life should be led (Barnes, 1991: p. 129).

In adult education and community digital inclusion projects, empowerment is more about freedom from control and external intervention than self-sufficiency. 


\section{Editorial}

For example, in a study of an adult IT community Centre, Roberts (2011) argued that there was a tendency for funders of the centre to push managers and tutors to push learners to pursue goals that would take then into formal education or employment (i.e. away from benefits and towards self-sufficiency). He observed however that many centre users rejected these official goals in favour of using technology to pursue their own "personal identity projects" such as becoming a better parent or increasing their volunteering activities within the local community. The importance of participants and community members functioning and succeeding without the need for outside, paternalistic intervention from the state or its representatives is therefore increasingly recognised. Cook \& Light (2006: p. 52) for example, express concern that most digital government services leave "most citizens as recipients of the services that 'enlightened' providers see fit to offer, rather than fully included, self-determining participants in a digital society". Indeed, in their description of how community members and formal educational institutions worked together to curate online content, Whitworth et al. (2012, this issue) bluntly state that "digital inclusion cannot arise through outside influence".

Empowerment is also increasingly being understood as individuals exerting control and choice by making decisions about appropriate or meaningful technology use. For example, Selwyn (2006) identified a hierarchy of engagement with technology; ranging from absolute non-users, to lapsed users and rare users. Pragmatism and perceived lack of relevance or "fit" with current life circumstances were recurring themes when exploring reasons behind levels of technology use. Results like this suggest a need to further our understanding of how the choices that people make regarding the nature and extent of their technology use might be influenced by technological factors (e.g. issues of access); personal factors (e.g. skill levels) or contextual factors (e.g. "life-fit"). A study by Seale et al. (2010) on the e-learning experiences of disabled students at university provides a clear example of how non-use might potentially be a positive phenomenon. Using a range of participatory methods, they found that whether and how disabled learners used technology to support their learning depended on their digital agility and digital decision-making. The students 'digital agility' was evidenced by their high confidence levels in relation to using technologies; high familiarity levels with a range of generic and specialist technologies and the wide range of strategies for making technologies work for them. Their decisions about technology use were influenced by a range of considerations including: what the affordances of the technology were; whether or not the technology in question "was the right tool for the job"; whether the technology was perceived to work or be impressive; whether the technology had a "study fit" and was aligned with the ways they felt they needed to study and whether the benefits of using the technology outweighed any perceived costs. Sometimes the results of this decision-making would be that students would decide not to use technologies. Whilst non-use in this example, can be linked to skills and abilities, it cannot necessarily be linked to skill deficiencies. Seale et al. (2010) for example suggest that the way the students made these decisions reflected a skilful, 'strategic fluency' and not simply a culturally structured choice.

\section{In the context of digital inclusion, in whose hands does empowerment lie?}

Seale et al. (2010) used their results to argue for the development of an empowerment model that encourages a move away from thinking about the deficits of disabled 
student that positions them as passive, reliant recipients of diagnosis and remediation services. They argued instead for a move towards an approach whereby the strengths of disabled students are recognised and the focus is on supporting learners in pursuing their own self-determined personal goals. Whilst disabled university students might be capable of making choices about their technology, these choices will be heavily influenced by the support provided by the universities in which they study. For example, in a study of whether the ICT-related needs of students with different disabilities are being met on campus at institutions of higher education, at home, and in digital learning contexts, Fichten et al. (2012, this issue) reveal some serious concerns around access: specifically around the availability of computers with adaptive software/hardware in specialized laboratories as well as with institutional ICT loan programs and funding for ICTs for personal use. McAndrew et al. (2012, this issue) position the university as a potentially "positive provider" to disabled students. Writing in the context of providing accessible online resources for students, they focus less on technologies and more on processes, systems and services that would promote accessibility across an institution.

The issues tied to disabled students and higher education provides support for the argument made by Selwyn and Facer (2007: p. 4) that digital inclusion requires both "informed and empowered choices" as well as "access to the resources required to enable them to act on these choices." The study of prison education presented by Pike \& Adams (2012, this issue) illuminates how lack of resources (access to and use of technology) can negatively influence the extent to which prisoners can make empowered choices about their technology use and education. Selwyn and Facer however, conceptualised resources in broader terms than just technological equipment. They are supported by the other papers within this special issue that suggest that access to people and expertise, is just as important as access to technical artifacts such as computer equipment. McAndrew et al. (2012, this issue) talk about "keeping the human in the loop"; Whitworth et al. (2012, this issue) discuss the vital role that local community-based "digital inclusion champions" can play and Berger \& Croll (2012, this issue) suggest that the relationship between teachers and learners is vital, particularly when the teacher can help to counter the apprehension that marginalized learners may feel about "performing in a domain in which their group is stereotyped to lack ability." This argument nevertheless recognizes that teachers often lack the expertise, training and time to support students, particularly within marginalised groups.

\section{Conclusion: digital inclusion and empowering practice}

Whilst in principle, it is relatively easy to accept the argument that supportive organisations and practitioners are necessary to enable learners to make empowered choices; what is more difficult to do is create these resources by defining and describing the exact kind of supportive practices that are the most effective or successful in terms of promoting the digital inclusion of marginalised learners. If we are unsure about what empowerment is, we are even less sure about what empowering practice is. This problem is confounded by the fact that there is little incentive for digital inclusion practitioners to critically evaluate their practices in a meaningful way. As Seale (2009) argued, much pressure is placed on achieving results in order to justify public funding, which can mean that practice is rarely subjected to detailed scrutiny in order to avoid showing glimpses of potential failure or weakness. 


\section{Editorial}

Seale relates this to the concept of "organisational slack" and the idea that digital inclusion projects need to be allowed to build opportunities into their practice or being creative and taking risks. Taking risks may result in occasional failures, but could, if underpinned by evaluative and reflexive activities, lead to the development of new, more effective digital inclusion practices: practices which might be empowering. In examining reports of digital inclusion projects, we must ask ourselves: is the practice of digital inclusion facilitators simply that which gets "reinforced, valued and rewarded" (Powell, 2007: p. 16) by policy makers and funding agencies, or is it something more creative and bolder; something which can challenge prejudices and stereotypes, counter risk-aversive cultures where appropriate as well as identify potential and raise aspirations? The contributions to this special issue lead conclusively to this bolder approach.

\section{References}

Barnes, C. (1991) Disabled People in Britain: A Case for Anti-Discrimination Legislation for Disabled People, Hurst/BCODP, London.

Becta (2001) The Digital Divide: A Discussion Paper, [online] Available at: http://partners.becta. org.uk/page_documents/research/digitaldivide.pdf

Castells, M. (2001) The Internet galaxy: reflections on the Internet, Business and Society, Oxford University Press, Oxford.

Cook, J. \& Light, A. (2006) 'New patterns of power and participation? Designing ICT for Informal and Community Learning', E-Learning, vol. 3, no. 1, pp. 51-61.

Digital Inclusion Team. (2007) The Digital Inclusion Landscape in England: Delivering Social Impact Through Information and Communications Technology, [online] Available at: http:// www.epractice.eu/files/media/media1881.pdf

Dutton, W. H. (1999) Society on the Line: Information Politics in the Digital Age, Oxford and New York, Oxford University Press.

Dutton, W. H., Shepherd, A. \& di Gennaro, C. (2007), 'Digital Divides and Choices Reconfiguring Access: National and Cross-National Patterns of Internet Diffusion and Use', in Information and Communications Technologies in Society, eds B. Anderson, M. Brynin, J. Gershuny, and Y. Raban, Routledge, London pp. 31-45.

Dutton, W. H., Helsper, E. J. \& Gerber, M. M. (2009) The Internet in Britain 2009, Oxford Internet Institute, University of Oxford.

Dutton, W. H \& Blank, G. (2011) Next Generation Users: The Internet in Britain, Oxford Internet Institute, University of Oxford.

Her Majesty's Government (2008) Delivering Digital Inclusion: An Action Plan for consultation, [online] Available at: http://www.communities.gov.uk/documents/communities/pdf/ 1001077.pdf

Lund, A. (2009) ICT as a mediation tool for intercultural practise. EUROSPHERE Working Paper Series, [online] Available at: http://www.eurosphere.uib.no/knowledgebase/wpsdocs/ Eurosphere_Working_Paper_20_Lund.pdf

Marks, K. (2009) The E-LAMP Projects, [online] Available at: http://www.shef.ac.uk/content/ 1/c6/02/73/58/elamp.doc

Padfield, P. \& Jordan, E. (2002) Interrupted Learning: Laptops and their Communicative Possibilities, University of Edinburgh, Edinburgh.

Padfield, P. \& Jordan, E. (2003) 'Are these really for us?" Laptops for teachers of pupils educated in outwith school settings, Edinburgh. STEP, [online] Available at: http://www.scottish travellered.net/research/laptops.pdf

Padfield, P. \& Jordan, E. (2004) Issues in school enrolment, attendance, attainment and support for learning Gypsy/Travellers and school-aged children and young people based in Scottish local authority sites, Edinburgh: STEP, [online] Available at: http://www.scottishtravellered. net/research/enrolment/STEP_enrolmentreport.pdf

Padfield, P. (2006) Learning at a distance supported by ICT for gypsies and travellers: Young peoples' views, Edinburgh. STEP, [online] Available at: http://www.scottishtravellered.net/ research/LADICT.pdf 
Powell, A. H. (2007) 'Access(ing) habits, attitudes, and engagements: Re-thinking access as practice', Computers \& Composition, vol. 24, pp. 16-35.

Roberts, G. B. (2011) What do you do with your community IT centre? Life stories, social action and the Third Space: a biographical narrative interpretive study of adult users of a community IT centre. PhD Thesis. University of Southampton.

Seale, J. (2006) E-learning and Disability in Higher Education: Accessibility Research and Practice, Routledge, Oxford.

Seale, J. (2009) Digital Inclusion. A research briefing by the Technology Enhanced Learning Phase of the Teaching and Learning Research Programme, [online] Available at: http:// www.tlrp.org/docs/DigitalInclusion.pdf

Seale, J., Draffan, E. A. \& Wald, M. (2010) 'Digital agility and digital decision-making: Conceptualising digital inclusion in the context of disabled learners in higher education', Studies in Higher Education, vol. 35, no. 4, pp. 445-461.

Selwyn, N. (2004) 'Reconsidering political and popular understandings of the digital divide', New Media \& Society, vol. 6, no. 3, pp. 341-362.

Selwyn, N., \& Facer, K. (2007) Beyond the Digital Divide: Rethinking digital inclusion for the $21^{\text {st }}$ Century, Bristol: FutureLab, [online] Available at: http://www.futurelab.org.uk/ resources/documents/opening_education/Digital_Divide.pdf

Technology Enhanced Learning Programme (2011) Inter-Life Project Press Release, [online] Available at: http://tel.ioe.ac.uk/2011/03/inter-life/ 